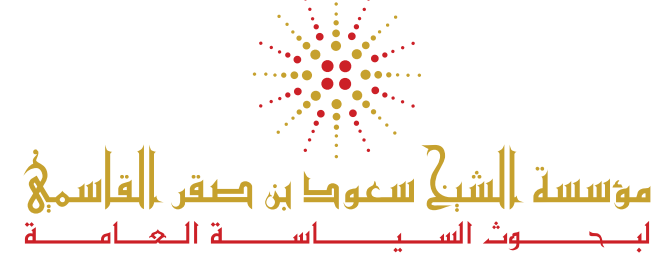

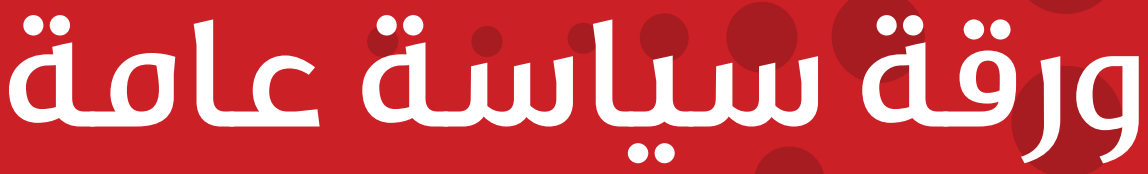

\section{تطوير وتنفيذ حملات توعية عامة حول سرطان الثدي في دولة الإمارات العربية المتحدة: دراسة حالة لإمارة رأس الخيمة}

دانيا أبو عواد، سيدةز. حسين، مارتن ماكي وباتريك برينان، جامعة سيدني

\section{المقدمة}

يعد سرطان الثدي أكثر أنواع السرطانات الخبيثة شيوعاً لدى النساء في دول مجلس التعاون الخليجي (Ravichandran Al Zahrani ، 2009)، ويتسبب بما يقارب التسب من 20\% من إجمالي عدد وفيات السرطان في غرب آسيا (الوكالة الدولية لأبحاث

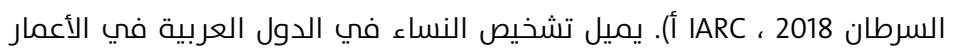

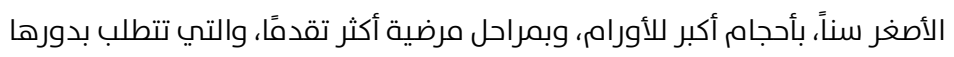
أشكالًا أكبر من العلاج (Chouchane و Boussen و 2013 ، Sastry). ينطبق هذآ أحذا الحال أو التشخيص المتأخر على دولة الإمارات العربية المتحدة، حيث يعتبر سرطان الثدي ، السبب الرئيسي لوفيات السرطان، وهو ما يمثل 26.4\% من الوفيات (ARC ، 2018 ب)، ويعزى السبب وراء ذلك إلى قلة استخدام برامج الفحص المتاحة ومعدلات مشاركة منخفضة للغاية فيما يتعلق بممارسات الفحص (الشرباتي، شيخ ، ماثيو، و البياتي، 2013). من شأن الكشف المبكر أن يسمح بخيارات علاج أكثر، وتدخلات أقل، وسيحّسن جودة حياة المصابات مما يمنحهن حياة أطول، ويقلل عدد الوفيات

المبكرة (مجلس السرطان في أستراليا، 2018).

وجدت دراسة أجريت في عامم 2017 في إمارة رأس الخيمة، بدولة الإمارات العربية

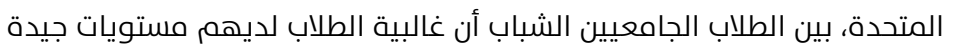
من الوعي أو المعرفة حول سرطان الثدي (رباني، متاسين، ناصر، و حسين ، 2017)، في حين أظهرت دراسة مماثلة أجريت في عام 2018 بين النساء فوق عمر 30 عامًا أن مستويات المعرفة لديهن كان أقل. علاوة عله ذلك، سلط المشار المشاركون في الدراسة الضوء على العديد من العوائق والتصورات حول فحص الثدي التي تمنع مشاركتهم في ممارسات الفحص (البيشان و ماكي و حسين برينان ، 2018). في الوقت الذي يتم فيه عقد برامج توعية وفحص خاصة بسرطان الثدي في العديد من المؤسسات في جميع أنحاء رأس الخيمة لتحسين معرفة المرأة وزيادة معدلات المشاركة في الفحص، من المهم جداً السعص نحو تحديد النُهج المؤثرة والفعالة من حيث التكلفة في الوصول إلى مختلف الفئات المستهدفة، مثل تفصيل المعلومات للنساء في الفئات العمرية أو مراحل الحياة المختلفة، وتشجيع النساء اللواتي لا يشاركن في الفحوصات على المشاركة في فحوصات السرطان الروتينية (براون، كير، هاودي و دارزي، 2012). ستحسن معدلات المشاركة

\section{الملخص التنفيذي}

يعتبر سرطان الثدي السبب وراء أكثر

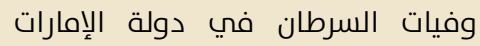

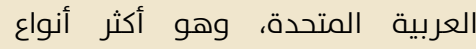

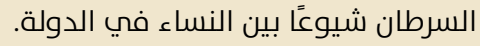
بالوقت الحالي، لا تزال مشاركة النساء النواء النواء

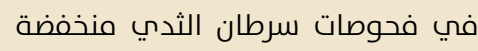

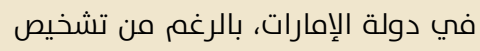

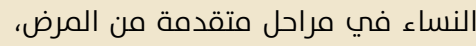

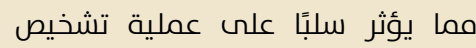
المرض ومعدلات البقاء على قيد الحياة. سيتيح الكشف المبكر توفير المزيد من خيارات العلاج، ويحسّن ظروف البرّاء على قيد الحياة، ويقلل من عدد الوفيات العلات المبكرة. تحتاج حملات التوعية الصحية وخدمات الفحص إلى دراسة العوائق التي تمنع النساء في دولة الإمارات إلتحات العربية المتحدة من إجراء الفحوصات المبكرة، وستساعد على ترويج طرق إجراء العردوة مستهدفة لتشجيع مشاركة النساء

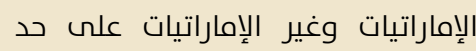
سواء على إجراء الفحوصات المبكرة. تستكشف ورقة السياسة هذه استفادة إدواء الفرداء

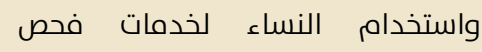
سرطان الثدي والخدمات الصحية الأخرى فحصات الخدمات

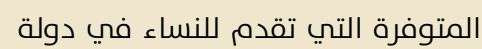
الإمارات، وتركز ايضاً عله التعرف عله

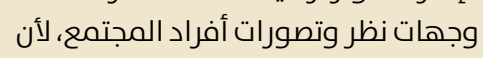
ذلك يقدم تفسير حول ردود أفعالهم وخياراتهم، بهدف زيادة الوعي وتنفيذ استراتيجيات وحملات فعالة، والتواصل بفعالية اكبر، وتعزيز مستوى المعرفة لدى الاخصائيين المهنيين الصحيين حول

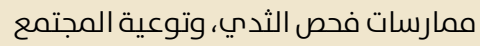
حول الدور المهم الذي تلعبه المنظمات والمؤسسات في تثقيف المرضس. من الدورات خلال الاعتماد على تصورات ووجهات فئ نظور النساء والممرضات وممثلي المنظمات الصحية، تختتم ورقة السياسة هذه والهمات

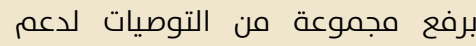
الحملات العامة الفعالة لمحاربة مرض سرطان الثدي وتعزيز مستوى مشاركة النساء لإجراء فحص الثدي. 
تشخيصهن في مراحل متأخرة. وفقًا لمنظمة الصحة العالمية (2007)، يجب أن تنصب أهداف برامج الكشف والفحص المبكر على تقليل النسبة المئوية للنساء اللاتي يتم تشخيصهن في المراح المراحل

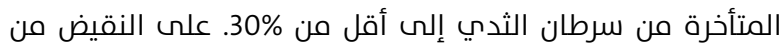
ذلك، الأمر الذي يستدعي القلق، تم تشخيص ما يقرب من 60\% من

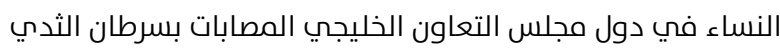
في مراحل متقدمة، مع وجود انتشار للورم الخبيث بشكل كبير،

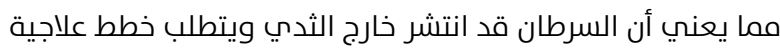

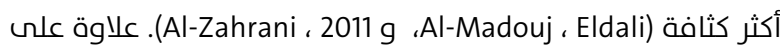
ذلك، كشفت دراسة اجريت بين النساء المصابات بسرطان الثدي في أنساء

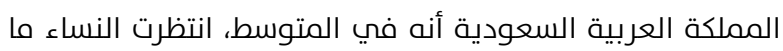
يقرب من أربعة أشهر بعد ملاحظة الأعراض لأول مرة قبل التماس العناية الطبية، مع تشخيص أكثر من نصفهن في مراحل متقدمة الرة

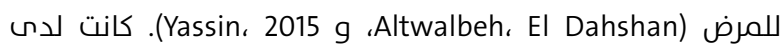
معظم النساء المصابات بسرطان الثدي في دولة الإمارات العربية المتحدة كتلاً في الثدمي ولكنهم لمم يطلبوا المشورة الطبية إلا أن

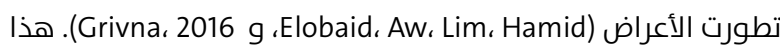
التأخير في التماس العناية الطبية كان يمكن أن يمنع من انتشار المرض ويؤكد على أن الكشف المبكر لسرطان الثدي يمكن أن يساعد العدان

في منع عواقب وخيمة محتملة.

ساعدت برامج الفحص في دولة الإمارات العربية المتحدة على تقليل عدد الأشخاص الذين يتم تشخيصهم في مراحل متقدمة من

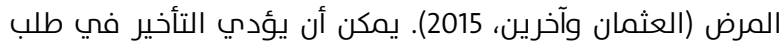

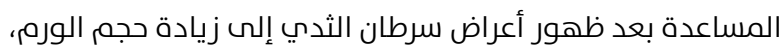
وينجم عنه استفحال المرض وتشخيصه في مراحل متقدمة، مما يؤدي إلى خفض معدلات البقاء على قيد الحياة وزيادة معدلات

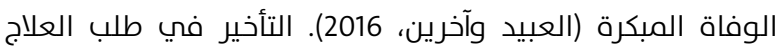
هو نتيجة المعرفة المحدودة بسرطان الثدمي وأعراضه، وقلة المعلومات حول أهمية التشخيص المبكر، التهي تؤثر جميعاً على اله مستوى البقاء على قيد الحياة ونوعية حياة المصابات. الغرض من الجمع بين الأساليب الثلاثة هو توفير فهم أفضل حول التعقيدات التي تحول دون مشاركة النساء في عملية فحص الثدي في إمارة رأس الخيمة. على وجه الخصوص، ستمنح نتائج هذه النهج المشتركة صانعي السياسات بالتوجيهات اللازمة لتحديد دور المهنيين والمنظمات الصحية من أجل تحسين مشاركة النساء في عملية الفحص (الطوالبة وآخرون، 2015).

\section{العوامل التي تعيق النساء من الخضوع للفحوطات وألمشاركة في عملية

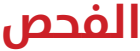

إن فهم مواقف النساء تجاه سرطان الثدي، وأسباب ترددهن في طلب المساعدة الطبية، وإمكانية حصولهن على الخدمات الصحية أمر مهم من أجل تحديد العوائق التي تحول دون إجرائهن للفحوصات، وتعزز معرفة المهنيين والمنظمات الصحية حول الطرق
المتزايدة معدلات الاكتشاف المبكر، التي بدورها ستساعد الخبراء والمعنيين على التعرف على العلامات التحذيرية، مما يزيد بالتالي

معدلات البقاء على قيد الحياة (منظمة الصحة العالمية، 2007). تستند ورقة السياسة هذه على نتائج دراسة أجريت من قبل البيشان وآخرين(2018)، 'توضيح استخدام النساء لخدمات فحص الثدي، وطرق هُ هُه تشجيعهن على المشاركة في هذه الفحوصات، ومستوى معرفة المهنيين الصحيين، وحملات فحص الثدي المتاحة في إمارة رأس الخيمة، وطرق الإعلان والتوظيف. الغرض من الجمع بين الأساليب الثلاثة هو توفير فهم أفضل للتعقيدات حول مشاركة النساء في فحوصات الثدي في إمارة رأس الخيمة. ستزود نتائج هذا النهج

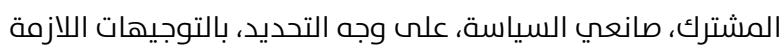
لتحديد دور المهنيين والمنظمات الصحية من أجل تحسين مشاركة النساء في عملية الفحص.

يعرض القسم الأول من ورقة السياسة النتائج من مناقشات مجموعات التركيز التي أجريت مع النساء، حول تفاصيل مشاركتهن

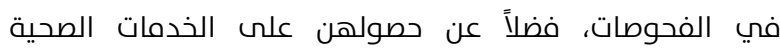
واستخدامها. يقدم القسم الثاني نتائج عامة من الاستبيانات التي أكملها ممرضو المجتمع والمستشفيات فيما يتعلق بمعرفتهم وقدرتهم على نقل المعلومات حول سرطان الثدي إلى مرضاهم. يعرض القسم الثالث نتائج المقابلات المتعمقة التي أجريت مع ممثلين من مختلف المؤسسات الصحية، لاستكشاف طريقة عمل هذه المؤسسات من أجل تحسين الوعي حول سرطان الثدي وتعزيز مشاركة النساء في عملية الفحص. باستخدام هذه العناصر الثلاثة المختلفة، تختتم الدراسة برفع التوصيات حول كيفية تحسين الوعي بسرطان الثدي وتعزيز المشاركة في برامج الفحص في إمارة رأس الخيمة والإمارات العربية المتحدة عموماً وخارجها.

\section{المشاركة فمي عملية فحص الثدمي وتشخيص سرطان الثُدية في}

لا زالت نتائج الدراسات الحالية تظهر معدلات مشاركة منخفضة في فحوصات سرطان الثدي، فضلاً عن مستويات منخفضة من المعرفة

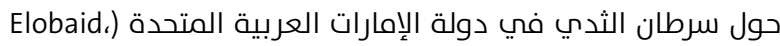
Aw، Grivna المثال، فقط 13.9\% من النساء الإماراتيات اللواتي شملهن المسح في عامم 2009 فوق عمر 40 سنة خضعن لفحص تصوير الثدي الشعاعي خلال فترة زمنية مدتها عامين (So وآخرين، 2018).

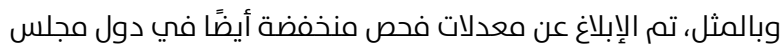

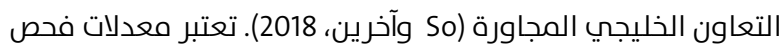
الثدي المنخفضة مصدر قلق صحي رئيسي للمجتمع حيث أن برامج الفحص لا تكون فعّالة إلا إذا نجحت في فحص أكثر من 70\% من السكان المستهدفين² (منظمة الصحة العالمية، 2007). يساهم انخفاض معدلات المشاركة في الفحص، والتأخيرات اللاحقة في طلب المساعدة عند الحاجة، بزيادة عدد النساء اللاتي يتم 
المقطعي للثدمي. قد يرجع ارتفاع مستوص المعرفة لدى المشاركات إلى حقيقة أن الغالبية العظمى منهن من فئة الخريجات واللواتي ئرجعات حصلن على تعليم عالٍ (74\% حاصلات على شهادة جامعية). أفادت المشاركات بالحاجة إلى إشراك الفتيات في الفحوصات الذاتية للثدي وفحوصات الثدي السريرية ليصبحن أكثر ارتياحاً مع عملية فحص أجسادهن وعند خضوعهن للفحص من قبل الأطباء، خاصة وأن سرطان الثدي يمكن أن يؤثر أيضًا على الشابات. أكدت معظم آدهم النساء

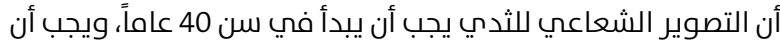
يتهم إجراؤه سنويًا أو كل سنتين، ومن الردود الشائعة الأخرى أن يبدأ الفحص بعد عمر 35 و 45 عاماً. ومع ذلك، أشارت المشاركات إله أنه إذا كانت لديهم أعراض أو كانوا أكثر عرضة للإصابة بسرطان الثدي، فسيخضعون لتصوير الثدي الشعاعي في وقت أبكر أو يواظبون عله القيام بذلك بصورة أكبر.

أشارت العديد من النساء في كل مجموعة إلى أنهن مارسن الفحوصات الذاتية للصدر، لكن بعضهن فقط مارسنها شهريًا. كانت النساء في المجموعات التي تبلغ من العمر 34-45 عامًا أكثر عرضة لإدراج أسباب أخذ فحوصات الثدي السريرية، مثل وجود أعراض

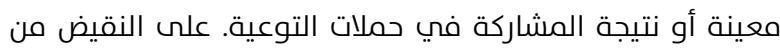
ذلك، أفادت النساء الأكبر سناً عن خضوعهن لفحص الثدي السريري بشكل أكثر انتظامًا أو أثناء الفحوصات الصات الصحية. معظم النساء في الفئات العمرية الأكبر سناً خضعن لتصوير الثدي الشعاعي. المشاركات اللواتهي ذكرن بأنهن لم يخضعوا لهذا الفحص وأكدوا أنهم سيشجعون الآخرين على إجراء الفحص، ولكنهم تجاهلوا إجراء الفحص لأنفسهن. النساء الأصغر سنًا خضعن لتصوير الثدي الشعاعي عندما كانت لديهن أعراض، واللواتي لم يخضعن لتصوير الثدي الشعاعي أكدوا أنهم سيجرونها إذا لزمم الأمر. على سبيل المثال، ذكرت إحدى المشاركات الإماراتيات التي تراوح عمرها

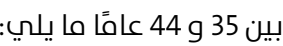

إذا كنا خائفين من شيء ما أو شعرنا بشيء غير طبيعي، فسوف نطلب المساعدة من الطبيب. بعد الفحص السريري سيتحقق الطبيب من الأمر ... إذا لزم الأمر سنقوهم بإجراء التصوير الشعاعي.

\section{2. المواقف تجاه سرطان الثدي}

أوضحت النساء في كل مجموعة من مجاميع التركيز أنهم لا يعتقدون أن معتقداتهم الدينية أو الثقافية يمكن أن تتسبب أو تؤدي إلى الإصابة بسرطان الثدي. بينما ذكرت بعض النساء غئهاء الإماراتيات أن الناس في وطنهم قد تكون لديهن مواقف مختلفة. وشملت الأمثلة الأشخاص في المناطق عالية الخطورة التي قد تتبع سلوكيات غير صحية لأنهم مقتنعون بأنهم سيصابون بالسرطان مهما كان الأمر، وبعض النساء يذهبن إله الطبيب فقط للتحقق من الأعراض وليس للوقاية من المرض. بالإضافة إلى ذلك، عند الذهاب إلى المواعيد الصحية، كان من الشائع بالنسبة للنساء في كل مجموعة التأكيد على أنهن يذهبون
التي يمكنهم فيها تشجيع النساء وتمكينهن من أجل المشاركة. إن تأثير المجتمعات والمنظمات على السلوكيات الصحية الفردية مسألة معترف فيها في النموذج البيئي الاجتماعي (منظمة الأممى المتحدة للطفولة يونسيف ، 2014). النموذج البيئي الإجتماعيي SEM النموذج، محاطًا بتأثيرات من العلاقات الشخصية أو المجتمعية أو أو التنظيمية أو السياسات أو البيئات التنظيمية (Kuykendall، 2018؛ منظمة الأمم المتحدة للطفولة يونيسيف، 2014). من المهم جداً الاعتراف بالتعقيدات أو العوامل المتعددة التي تلعب دورًا وتؤثر علس السلوكيات الصحية للأفراد (Kuykendall ، 2018؛ منظمة الأمم المتحدة للطفولة يونيسيف، 2014)، ويجب معالجة كل عامل أو أخذه بنظر الاعتبار عند إعداد الحملات لتعزيز المعرفة من خلال التوعية الصحية، مثل حملات سرطان الثدي.

تضع ورقة السياسة هذه نتائج الدراسة والتوصيات في سياق النموذج البيئn الاجتماعي، وأدرجت مستوى معرفة وتصورات النساء بشكل فردي وجماعي، وكذلك الممرضات الذين يعملون داخل المجتمع، وممثلي المؤسسات الصحية في إمارة رأس الخيمة.

\section{مستتوn معرفة النساء ومواقفهن تجاه سرطان الثدي وعملية فحص الثّدي}

تضمنت هذه الدراسة النوعية عقد ستة مناقشات جماعية مركزة مع مجموعة من النساء في إمارة رأس الخيمة بهدف الحصول على منظور متعمق حول تصورات ومواقف النساء حول مواضيع تتعلق بسرطان الثدي. تم تشكيل مجموعة من النساء الإماراتيات ومجموعة أخرى من النساء غير الإماراتيات لكل من الفئات العمرية

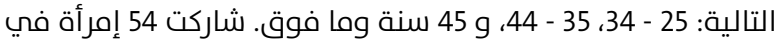
الدراسة؛ 28 منهن من الإماراتيات (52\%) و 26 من من غير الإماراتيات (48\%) معظمهن من دول أوروبية (17\%) أو دول آسيوية (15\%). تراوحت أعمار النساء ما بين 24 و 65 سنة، بمتوسط عمر 39. كانت غالبية النساء من فئة ما قبل سن اليأس (72\%)، المتزوجات (54\%)، اللواتي لديهن أطفال (56\%)، اللواتي درسن في الجامعة (76\%)، الموظفات (44\%) واللواتي يعيشون في المناطق الحضرية (78\%) .3 3 طلب من المشاركات إكمال مسح ديموغرافي قصير، قبل المشاركة في مناقشات مجموعات تركيز شبه منظمة، وكانت هناك ما يقرب من ثمانية مشاركات في كل جلسة لمجموعات التركيز. تم تقسيمم فتهم الأسئلة إلى ثلاثة أقسام: المعرفة حول فحل فحص سرطان المان الثدي، والمواقف تجاه سرطان الثدي، والمعرفة حول الخدمات الصحية المتوفرة للنساء. تم توجيه المناقشات من قبل باحثين من جامعة سيدني، وتم ترجمة النتائج وتحليلها باستخدام التحليل الموضوعي.

1. المعرفة حول فحص سرطان الثدي كانت جميع مجموعات التركيز على دراية بالفحوصات الذاتية للثدي (BSE)، وفحوصات الثدي السريرية (CBE)، والتصوير الشعاعيي 


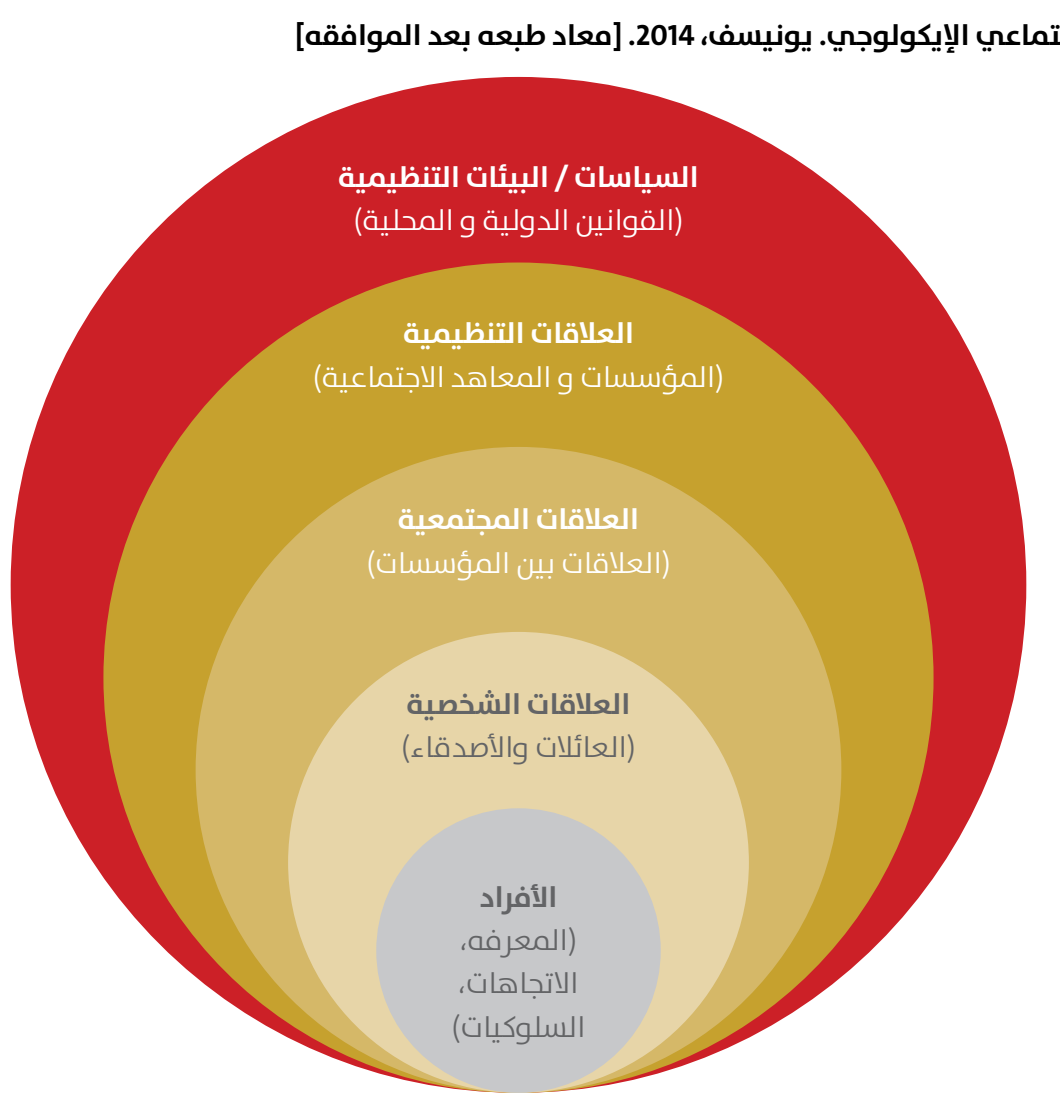

بالنسبة للخدمات الحكومية أيضًا، هناك فترات انتظار طويلة قبل الحصول على الخدمة الصحية، ولكن

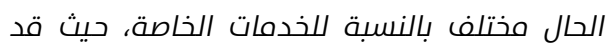

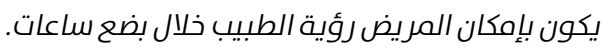

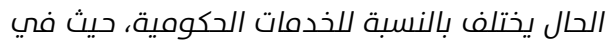
العادة يستغرق الحصول على موعد وقتًا طويلاً

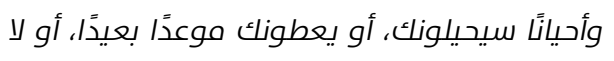

يوافقون عله رؤيتك إلا إذا كانت حالة طوارئ.

قالت المشاركات إن خدمات علاج الأورامم متوفرة في دولة الإمارات، ولكن إذا لم تكن متوفرة في مستشفى معين، فسيتم إحالة المرضه إلى مستشفيات خارج إمارة رأس الخيمة.

\section{خدمات الرعاية الصحية الخاصة}

أفادت النساء الإماراتيات وغير الإماراتيات استخدامهن للخدمات الصحية الخاصة، لكنها كانت أكثر شيوعًا بين غير الإماراتيات. ووصفت معظم النساء في كل مجموعة الخدمات الصحية الخاصة والمتخصصة بأنها سهلة الاستخدام ومن السهل حجز المواعيد، وليس هناك حاجة إلى وجود إحالة من طبيب الأسرة، وليس هناك فترات انتظار. أفادت النساء غير الإماراتيات بأن الخدمات الخاصة المتاحة تلبي جميع احتياجاتهم. ومع ذلك، كانت النساء أقل حماساً بشأن الفترات اللازمة للحصول على المواعيد في العيادات الخاصة، وتم وصف هذه المواعيد بأنها قصيرة وتجرى على عجل.

\section{الأجور والتأمين}

وصفت النساء تكلفة الحصول على الخدمات الصحية المتخصصة

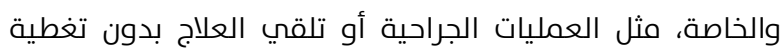
تأمينية، بأنها باهظة الثمن، خاصة عند المقارنة مع البلدان الأخرى. بالنسبة لهؤلاء النساء، قالوا أنهن يفضلن الذهاب دون الخدمات
بمفردهن. ومع ذلك، فضلت بعض النساء زيارة الطبيب بصحبة شخص آخر من أجل الحصول على الدعم المطلوب. إذا حدثت تغيرات غير

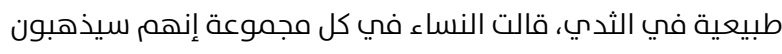
إله الطبيب أو المستشفى على الفور، ولكن هذا الجواب لم يكن مماثلاً لجميع المشاركات، حيث أفادت بعضهن أنهن ربما لن يذهبن

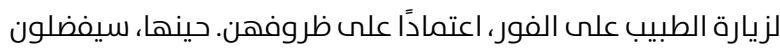
الحصول عله المعلومات من الإنترنت ويراقبون بأنفسهن التغييرات.

\section{3. الخدمات الصحية المقدمة للنساء} خدمات الصحة العامة

أشادت المشاركات بالخدمات والموارد المقدمة لهم في دولة الإمارات العربية المتحدة. بشكل عام،، شعرت المشاركات أنه لا توجد الخدات خدمات صحية عامة غير متوفرة لهن، وأن الخدمات جميعاً تفي باحتياجاتهن. هذه الخدمات تستخدم في الغالب من قبل المواطنات الإماراتيات، خاصة بين الإماراتيات الأكبر سناً اللواتي يفضدهات الخده الخدمات الخدات

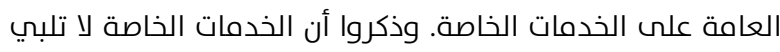
دائمًا احتياجاتهم، في حين أن الخدمات العامة متاحة لهم مجانًا

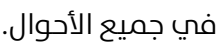
ومع ذلك، أوضحت النساء أن المواعيد الطبية غالبًا ما تكون طويلة الأمد، مما قد يؤخر الاخريات اللواتي ينتظرن. أيضا، الأطباء عادة لا لا يحترمون جداول المواعيد مما يزيد من أوقات الانتظار، وهو غير ملائمم للنساء اللواتي لديهن أطفال أو وظيفة. يمكن أن تتسبب قوائم الانتظار الطويلة للمواعيد أيضًا على تشجيع بعض النساء الذاء الذهاء للذهاب إله الإمارات الأخرى للحصول على خدمات الصحة العامة أو دفع الأموال مقابل استخدام الخدمات الخاصة. قالت إحدى النساء الإماراتيات: 
بسرطان الثدي وعملية الفحص، وتوضيح الطريقة التي قاموا فيها بتثقيف المرضس في أماكن عملهم. غطت الورشة إحصائيات سرطان الثدي والتشريح والتشخيص والعلاج. بعد ورشة العمل، يتطلب من الممرضات تعليم الممرضات الأخريات حول محتوى الورشة. تتناول الاستجابات الواردة أدناه استجابات الممرضات حول طرق التشخيص المختلفة لسرطان الثدي.

\section{1. المعرفة حول كيفية إجراء فحص الثدي الذاتي}

يعرض الجدول رقم 2 أيضًا نتائج استجابات الممرضات حول السن المفضل للنساء من أجل إجراء فحص الثدي، ومدى تواتره، ومستوى ثقتهن قبل وبعد ورشة العمل التدريبية. أظهرت النتائج أن جميع الممرضات يعرفون كيفية أداء فحص الثدي الذاتي، وقد تعلّلم معظمهم ذلك خلال دراساتهم التمريضية. مارست من الممرضات فحص الثدي الذاتي، لكن نصفهم اوضحوا أنهم لم يفعلوا ذلك باستمرار. عموماً، أفادت نصف الممرضات أنه يجب ممارسة فحص الثدي الذاتي ابتداء من عمر 20 سنة، لكن وردت اجابات أخرى مثلاً عند البلوغ وعند عمر 30 سنة من بعض الذهم الذمرضات.

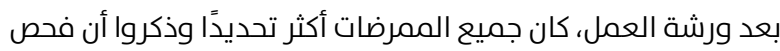
الثدي الذاتي يمارس في سن 20 عامًا. أغلبية المشاركات قدموا إجابة صحيحة حول ضرورة إجراء فحص الثدي الذاتي شهريًا، وذكرت ممرضتان أنه يجب إجراؤه خلال كل عملية استحمام، وهذواء وهذا الجواب لم يتغير منذ بدء ورشة العمل وبعدها. قبل ورشة العمل، كانت الممرضات واثقات من تعليم المرضى كيفية أداء فحص الثدي الذاتي، لكن ثلث الممرضات أرادوا مراجعة معلوماتهن بعد ورشة العمل للشعور بالمزيد من الثقة. قالت أحدى المشاركات: قبل ورشة العمل: إذا كان لدي المزيد من المعرفة والمهارات حول عملية الفحص الذاتي للثدي، فسوف أقوم بذلك بثقة أكبر. بعد ورشة العمل: بعد المحاضرة لدمي المزيد من المعرفة والمهارات للقيامم بذلك من أجل الآخرين.

\section{2 المعرفة حول فحص الثدي السريري}

تبين أن 40\% من المشاركات في الدراسة خضعن لفحص الثدمي السريري، على الرغم من أن 82\% منهن كانوا أقل من 40 عامًا. جميع المشاركات تلقوا المعلومات حول سرطان الثدي من خلال دراساتهم التمريضية، لكن مشاركتان فقط خضعن للتدريب على سرطان الثدي في العمل. حددت ما يقرب من نصف الممرضات بشكل صحيح أن فحص الثدي السريري مطلوب للنساء في سن 40، لكن الباقيات ذكرن أن الفحص يجب أن يتمم بعمر 20 أو 30 أو 45 عاماً، أو للنساء اللواتي لديهن أعراض. بعد ورشة العمل، ذكرت الأغلبية أن فحص الثدي السريرمي مطلوب للنساء بعمر 40 عاماً، وذكرت مشاركتان أنه مخصص للنساء المصابات بأعراض في أي عمر. أفادت معظم الممرضات بشكل صحيح أن فحص الثدي السريري يتم إجراؤه

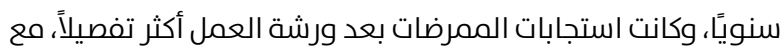
تأكيد اغلبية المشاركات بأن "النساء المعرضات لمخاطر عالية يجب المبات أن يخضعن للفحص من ستة إله اثني عشر مرة في السنةه (انظر

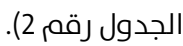

تبين أن 82\% من الممرضات عملن في المنظمات التي تقدم خدمة
التي يحتاجون إليها، أو الانتظار حتى تصبح حالة طارئة، أو الانتظار حتى العودة إلى وطنهن للحصول على الخدمة. ومع ذلك، كانت المشاركات على دراية بالمخيمات الطبية الصحية في دولة الإمارات العربية المتحدة، أو الخدمات الصحية في مخيمات العمل، أو المخات الجمعيات التي تقدم فحوصات صحية مجانية لمجموعات محددة، أو حملات لمختلف المشاكل الصحية التي تقدم خدمات أو فحوصات

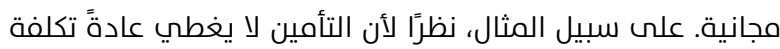
خدمات فحص الثدي، فإن النساء يسعين للحصول على عروض فحص مجانية أو مدعومة تكون متاحة عادةً في شهر أكتوبر، وهو شهر التوعية بسرطان الثدي على المستوى الدولي. قالت امرأة غير إماراتية تبلغ من العمر 45 عامًا:

من النادر جدا أن تغطي [شركات التأمين] تكاليف

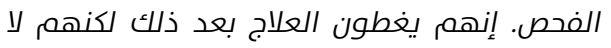

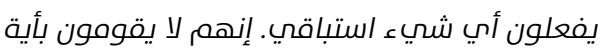

تغطية مسبقة.

مصادر المعلومات

ذكرت المشاركات في الدراسة أنه بالوقت الحاضر، تلقوا المعلومات حول سرطان الثدي أو حملات التوعية من مصادر مختلفة، بما في ذلك الكتيبات ووسائل التواصل الاجتماعي ووسائل الإعلام، وأطبائهم في المستشفيات ومراكز الرعاية الصحية الأولية والعيادات، وكذلك من وزارة الصحة و الوقاية (انظر الجدول رقم 1). ومع ذلك، كانت أكثر وسيلة مفضلة لتلقي المعلومات هي وسائل التواصل الاجتماعي وخدمة واتساب. كما أفادت المشاركات أنهن أيضًا يفضلون الحصول على المعلومات من الكتيبات والإعلانات الموجودة في أماكن الانتظار، وقراءة المواد المطبوعة، والإطلاع على معلومات موثوق فيها عبر شبكة الإنترنت، وطلبن إدراج تفاصيل الاتصال في الإعلانات حتى تتمكن النساء من متابعة المعلومات المقدمة (انظر الجدول رقم 1). بهدف تحسين الوعي بسرطان الثدي وتعزيز المشاركة في عملية فحص الثدي، ذكرت المشاركات أنه يجب عله النساء الحصول على معلومات من الأطباء أو الممرضات، وتلقي رسائل رسائل تذكير نصية على الهاتف المحمول حول فحوصات المتابعة من عيادات فحص الثدي، ويجب أن تكون هناك حملات أطول لفحص الثدي، ويكون

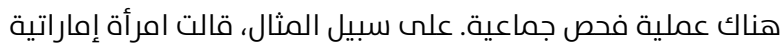

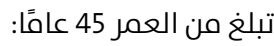
يفضل أن يكون هناك القليل من الاهتمامم. يجب عليهم الاتصال

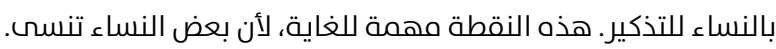

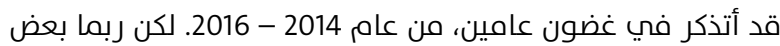

الناس ينسون ذلك.

\section{مستوم معرفة الممرضات بسرطان الثدي ومدص ثقتهم بتوعية الأخرين بسرطان الثدمي}

من أجل استكشاف معرفة الممرضات بشكل أفضل وتوفير بعض التثقيف حول سرطان الثدي، تم عقد ورشة عمل لتدريب 17 ممرضة

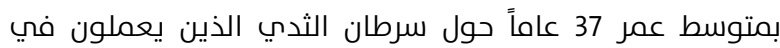
العيادات والمستشفيات العامة والخاصة والجامعات في إمارة رأس الخيمة. طلب من المشاركين استكمال استبيان تضمن مجموعة من الأسئلة المفتوحة قبل وبعد ورشة العمل حول معرفتهن 
الجدول 1: مصادر معلومات سرطان الثدي لدم النساء وأنشطة الترويج، بما في ذلك قنوات ووسائل الاتصال المفضلة

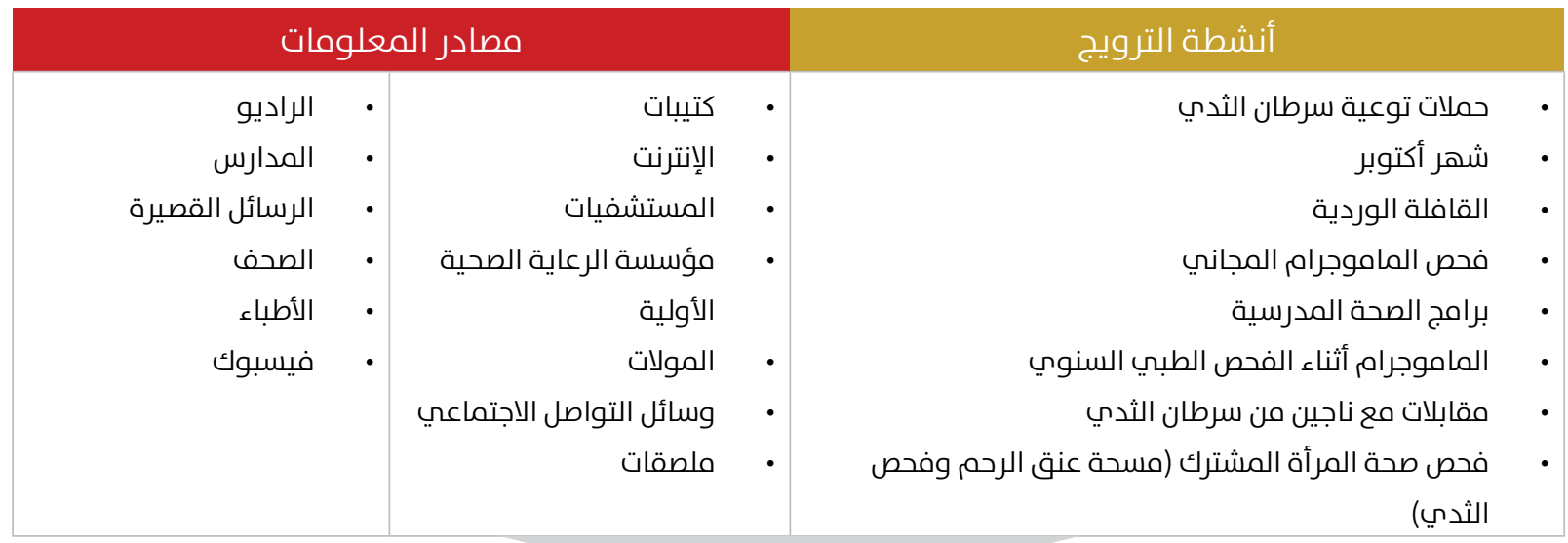

\begin{tabular}{|c|c|c|c|c|c|}
\hline \multicolumn{4}{|c|}{ وسائل الاتصال المفضلة } & \multicolumn{2}{|l|}{ الوسائل المفضلة } \\
\hline التشجيع من الرجال & & وسائل التواصل الاجتماعـي & - & إعلانات في مناطق الانتظار & - \\
\hline معلومات من الأطباء & - & الفيسبوك & - & معلومات موثوقة على الإنترنت & - \\
\hline والمتخصصون & & إنستغرام & • & إدراج تفاصيل الاتصال في الإعلانات & - \\
\hline خدمة مجانية & - & 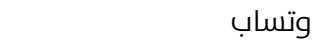 & • & رسائل تذكير قصيرة لمتابعة الفحوصات & - \\
\hline & & الهواتف المحمولة & • & حملات مستمرة أطول & - \\
\hline & & 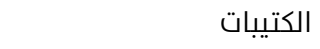 & • & دمج الفحص الجماعي & - \\
\hline & & المواد المطبوعة & - & & \\
\hline
\end{tabular}

4. ثقة الممرضات تجاه تثقيف المرضص

استكشف الجانب التالي من الاستطلاعات كيف تستخدم الممرضة

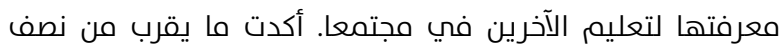

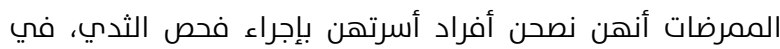
حين أكدت ما يقرب من 70\% من الممرضات أنهم نصحوا مرضاهمن بالقيام في ذلك. أكدت جميع الممرضات اللواتي يعملن في العيادات أو الجامعات أنهم قاموا بتوعية مرضاهم حول دمات عملية الفحص. بالمقابل، لم يكن لدى بعض الممرضات مثل أولئك الذين يعملون في غرفة العمليات فرصة لتوعية المرضس حول عملية فحص الثدي. هذا يشير إلى أن بيئات ومرافق العمل فهل مهمة التهة

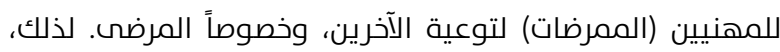
يجب تمكين الممرضات في هذه العيادات أو المؤسسات لأن ذلك سيساعدهن على تقديم المعلومات الصحيحة المطلوبة للمصابات بسرطان الثدي.

اعتبرت الممرضات أن ورشة العمل التدريبية "غنية بالمعلومات ... (نحن) تعلمنا المزيد عن فحص الثدي الذاتي، وفحص الثدي السريري، والعلامات والأعراض، وعوامل الخطر، وما إلس ذلكهُ، وتعتقد جميع الممرضات أنهن سيكونون قادرات على نقل واتل المعلومات التي اكتسبوها من ورشة العمل التدريبية إلى الممرضات الأخريات، حيث قالت أحدى المشاركات، »إنها مسؤولية كبيرة». تعتقد جميع الممرضات أنه من المهم تلقي التدريب حول سرطان الثدي في مكان عملهن لأنه يحسن معرفتهن الخاصة ويجعلهن على دراية بأثر سرطان الثدي لدم النساء في إمارة رأس

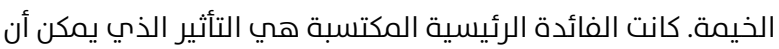

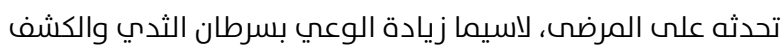

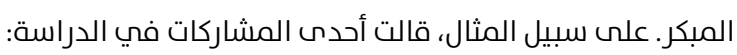

فحص الثدي السريرمي. تتفق 71\% من الممرضات أنه سيسمح لهن إجراء فحص الثدي السريري بالتعاون مع الأطباء. ومع ذلك، أفادت 60\% من الممرضات أنهن بحاجة إلى التدريب أو لمم يكونوا على ثقة حول كيفية إجراء فحص الثدي السريري. أفادت 40\% من المتبقيات أنهم يشعرون بأن فحص الثدي السريرمي مهم وأنهم يرغبون

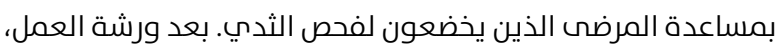
ذكرت الممرضات أنهم اكتسبوا المزيد من المعرفة حول فحص لدص الثدي السريري وشعروا بثقة أكبر من ذي قبل، لكن البعض أرادوا الحصول على المزيد من التدريب أو "بحاجة إلى ممارسة أكبر" و ”الفحص يمكن أن يساعد جميع النساء عله الكشف المبكر".

\section{3. المعرفة بالتصوير الشعاعي للثدي}

بالنسبة للتصوير الشعاعي للثدي، أفادت أكثر من نصف الممرضات بشكل صحيح أن التصوير الشعاعي للثدي يتم إجراؤه للنساء في سن الأربعين، ولكن القليل ذكروا أنه يجرى بعمر 30 أو 45 عاماً، لكن بعد ورشة العمل جميع المشاركات ذكروا أنه يجرى بعمر 40

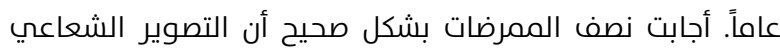
للثدي يجب أن يجرم كل عامين. ومع ذلك، بعض الردود الشائعة

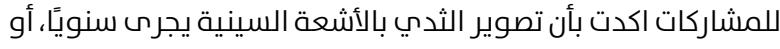

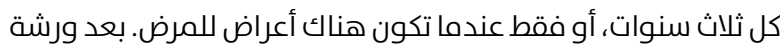

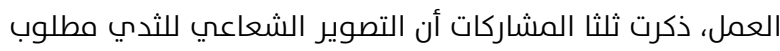
كل عامين، لكن الثلث لا زالت تعتقد أنه مطلوب سنويًا. يمكن أن يكون هذا نتيجة لزيادة تواتر التصوير الشعاعي للثدي للنساء المعرضات لمخاطر عالية مصحوبًا بمناقشة عوامل الخطر بما في ذلك الجنس والعمر وعوامل نمط الحياة الشائعة مثل التدخين وعدم ممارسة

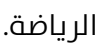


الجدول 2: مقارنات قبل وبعد فحص الثدي

\begin{tabular}{|c|c|c|c|}
\hline \multicolumn{4}{|c|}{ الفحوصات الذاتية للثدي } \\
\hline > 20 سنة & $\cdot$ & 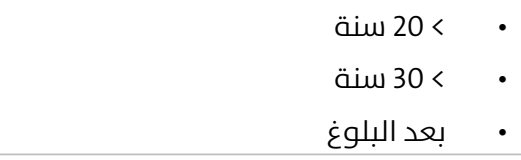 & العمر \\
\hline شهرياً & $\cdot$ & شهريًا أو كل دورة & التكرار \\
\hline 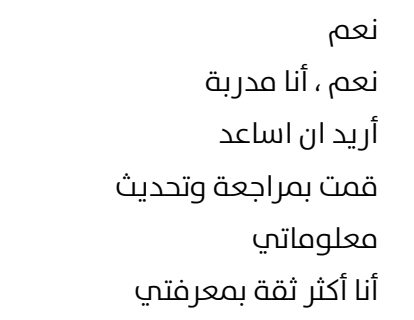 & • & • • • • • • & المستشفيات \\
\hline \multicolumn{4}{|c|}{ فحوصات الثدي السريرية } \\
\hline بعد & & قبل & \\
\hline > 40 سنة أو 40-69 سنة النساء & • & 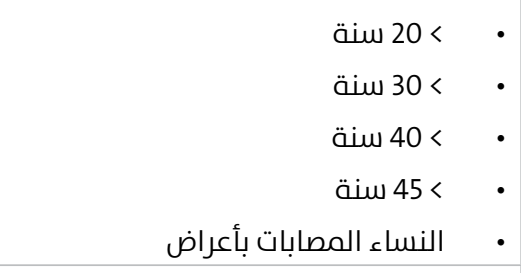 & 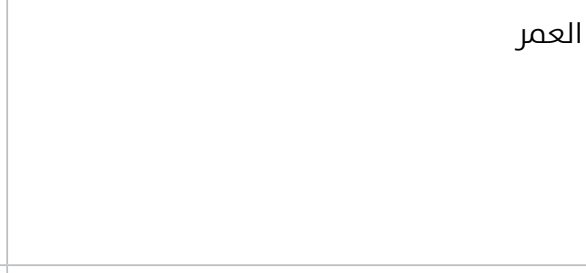 \\
\hline $\begin{array}{r}\text { المخاطر عالية و / أو أكثر إذا كانت } \\
\text { الأعراض منتين أو أكثر إذا كانت }\end{array}$ & $\cdot$ & 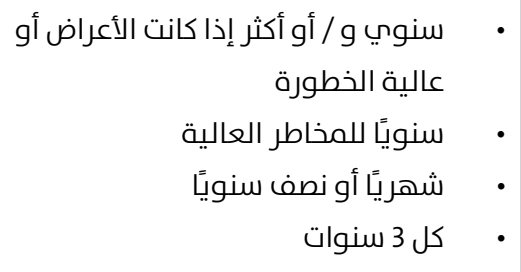 & التكرار \\
\hline 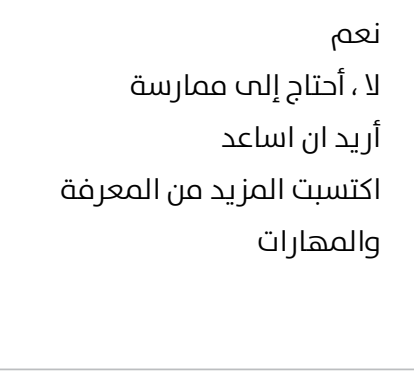 & $\begin{array}{l}\cdot \\
\cdot \\
\cdot \\
\cdot\end{array}$ & 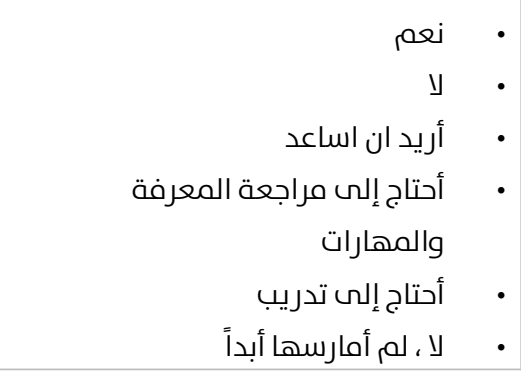 & الثقة \\
\hline \multicolumn{4}{|c|}{ تصوير الثدي الشعاعي } \\
\hline بعد & & قبل & \\
\hline > أعراض نساء 40 سنة 40-69 سنة و / أو & • & 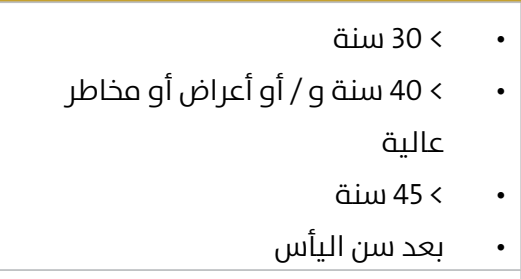 & 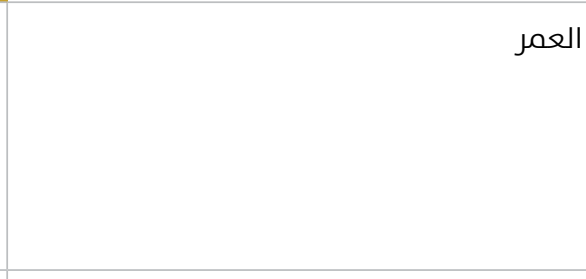 \\
\hline 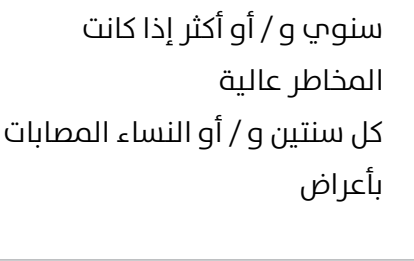 & $\bullet$ & 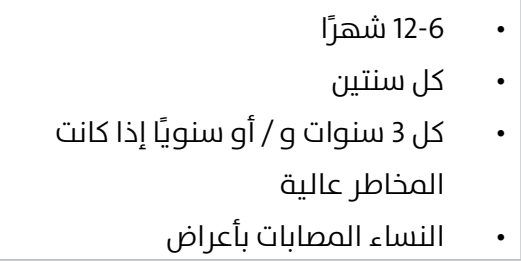 & التكرار \\
\hline
\end{tabular}


الموجودة في المنطقة. وذكر أحد ممثلي المنظمة:

عندما يسمعون عن الحملة سيكون الأمر أسهل عليهن. بإمكانهن رؤية الطبيب وجهاً لوجه والحصول على الاستشارة والنتائج على الفور.

عندما سُئلت المشاركات عما إذا كان من المفيد الجمع بين حملات صحية شهرية مختلفة، ذكرت الأغلبية أنه سيكون من الأفضل إبقاء الحملات منفصلة كما هي حاليًا نظرًا لأن كل تركيز صحي يحظة آنها باهتمامه المناسب وستكون الحملة أكثر فعالية. ومع ذلك، ذكرت بعض المشاركات أنه يمكن الجمع بين المواضيع التي تتعلق بصحة المرأة. أثناء الفحوصات الصحية العامة، يقوم بعض الأهرن الطباء والممرضات في العيادات أو المستشفيات بتوعية مرضاهم حول سرطان الثدي وأهمية الفحص الروتيني.

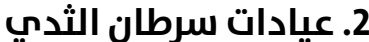

تم عقد حملات التوعية في عيادات سرطان الثدي بشكل متكرر على مدار العام وبشكل أكبر مقارنة بالمؤسسات الأخرى التي تقدم خدمات فحص الثدي، وكان هناك تركيز أكبر على ضمان جو إيجابي داخل العيادة. يتيح هيكل سير العمل في العيادة فحص المرضس وكان من قبل ممرضة وأخصائي، ويتم فحصهم واستلام نتائجهم بسرعة، مما يسمح لهم بالعودة إلى منازلهم دون انتظار طويل أو قلق فلق كبير. تتعاون العيادة مع منظمات أخرى من أجل إحالة النساء

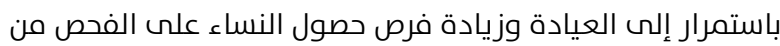
خلال زيادة تمويل هذه العملية.

\section{3. الاستراتيجيات الوطنية الخاصة بمرض السرطان}

اعتبر ممثلو المنظمة أن حملات وزارة الصحة أقوى وأكثر فاعلية من الحملات المحلية الأخرى، ويعد جزء من السبب لأن حملاتهم كانت ذات صلة بجميع السكان دون أن تقتصر على مرضس معينين داخل منظمة واحدة. معظم المشاركين إما دعموا أو عملوا بشكل مباشر

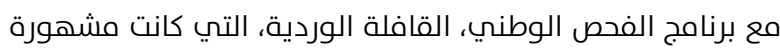
جداً في المنطقة. كما ساعدت وزارة الصحة عيادات فحص الثدي المحلية في الحصول على معدات فحص الثدي، بما في ذلك أجهزة التصوير الشعاعي للثدي. شجّعت وزارة الصحة الممرضات على الالتحاق ببرامج الفحص المبكر، وساعدت في رعاية التعليم

الجامعي للممرضات.

\section{4. نقاط القوة والضعف في الحملات}

شملت نقاط القوة للحملات التي تديرها المنظمات المختلفة وجود حضور كبير من النساء، وتم توعية المجتمع فيها من خلال العديد من الإعلانات والمنصات ووسائل التواصل الاجتماعي، ووجود طبيب يثق فيه الناس، وإمكانية توفير الفحص بصورة مجانية. لم تتغير الحملات كثيرًا مقارنة بالحملات التي تم عقدها في العقد الماضي، لكن مواقف النساء تحسنت، وأصبحت أكثر استباقية لمتابعة الفحصا، وهناك مخاوف أقل. ذكرت أحدى المشاركات:

معظم الحملات لا تتغير، لكن وجهة نظر المجتمع تجاه الحملات هو الذي يتغير. شعر الناس بالرغبة الكبيرة لكسب المزيد من المعرفة حول ما هو مفيد لصحتهم ورفاهيتهم.

كانت إحدى القضايا الرئيسية التي أثارها ممثلو المنظمة هي أن
من المهم جدًا توعية أفراد المجتمع لأن ذلك تقاد يساعدنا على تقليل عوامل خطر الإصابة بسرطان

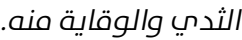

ذكرت الممرضات أيضًا أنه بشكل عام، النساء في دولة الإمارات العربية المتحدة يترددن في إجراء فحص الثدي الذاتي والتصوير الشعاعي للثدي بسبب نقص المعرفة، وعدمم فهم أهمية الفحص المبكر أو الإهمال الذاتي أو الانشغال الشديد. بالنسبة لفحص الثدي الذاتي، والتصوير الشعاعي للثدي، ذكرت الممرضات أيضًا بأن الحواجز تشمل تكلفة إجراء الفحص، والشعور بالخجل، وعدم

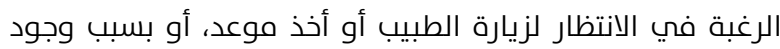
أية أعراض لديهن. لن تمارس النساء فحص الثدي الذاتي إذا لم يعرفوا كيفية إجراء ذلك، كما أنه يُنظر إله تصوير الثدي الشعاعي على أنه إجراء مؤلم.

\section{دور المنظمات في تحسين مشاركة النساء فصي عملية فحص الثندي}

من أجل استكشاف مبادرات المنظمات من أجل تحسين وعي النساء بسرطان الثدي ومشاركتهن في عملية فحص الثدي، تم إجراء مقابلات متعمقة مع ثمانية ممثلين من مختلف المنظمات الصحية في إمارة رأس الخيمة. وقد شارك جميع المشاركين في حملات أو برامج التوعية بسرطان الثدي داخل منظمتهم. أكمل المشاركون

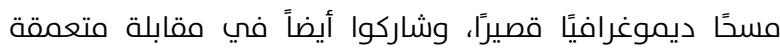
شبه منظمة. تطرقت الأسئلة إلى حملات المنظمات المعنية بسرطان الثدي، والبرامج الوطنية، والتغييرات التي تطرأ عند إجراء الحملات الإضافية. تم استخدام التحليل المواضيعي لتحليل

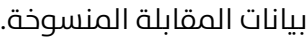

كان متوسط عمر المشاركين الثمانية 46 عامًا (تراوحت الأعمار ما بين 29 - 65 عاماً)، وهم يعملون في المستشفيات والعيادات والجامعات العامة والخاصة. حصل جميع المشاركين على تعليم عالٍ، ومعظمهم كانوا من العرق الآسيوي (75\%)، وتعلموا خارج دولة الإمارات (75\%)، وكانت لديهم خلفية تمريضية (50\%)، وعملوا في مستشفيات خاصة (50\%). تراوحت خبرتهم العملية بين سبع (ل15)، سنوات و 43 سنة، بمتوسط 17 سنة. تغطي الردود الواردة أدناه السمات المختلفة لحملات التوعية بسرطان الثدي التي تمم تقديمها في إمارة رأس الخيمة.

\section{1. حملات توعية المنظمات بسرطان الثدي}

جميع المشاركين يعملون في المنظمات التي لعبت دورًا في توعية المجتمع بسرطان الثدي وعقد حملات التوعية داخل مؤسستهم والمجتمع. يتم التخطيط للدورات والبرامج وحملات التوعية في التهات الجامعات والمستشفيات ومراكز التسوق والعيادات وفقًا لأولويات دولة الإمارات العربية المتحدة أو التركيز الصحي المحدد لشهر معين. كانت الاستشارات المجانية شائعة، مع تقديم خدمات فحص التصوير الشعاعي للثدي المدعومة أو المجانية لمساعدة النساء غير القادرات على تحمل تكاليف فحص الثدي. سهّلت الحملات الوطنية والإقليمية إمكانية وصول النساء بسهولة إلى فحص الثدي وتلقي الاستشارات من الاطباء من خلال توفير خدمات الفحص في مختلف الأماكن العامة المفتوحة والمناطق الريفية. كانت الحملات امتدادا للخدمات المقدمة في عيادات سرطان الثدي 
"الوقاية خير من العلاج" عبارة شائعة مستخدمة، وتشجع على اتخاذ موقف أكثر استباقية تجاه الصحة. ومع ذلك، لم تكن لدى أي من المشاركات تأمين صحي يغطي التصوير

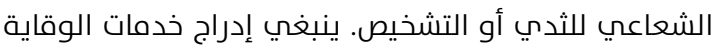
والفحص عبر مختلف المشاكل الصحية في التغطية التأمينية، بما في ذلك التصوير الشعاعي للثدي.

فضل المشاركون تلقي المعلومات مباشرة من الأطباء أو العاملين الصحيين. يمكن للموظفين المدربين أو الممرضات

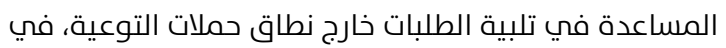
العيادات أو المستشفيات، من خلال توفير التعليم الفردي أو أو الجماعي، والتي كانت فعالة في زيادة المشاركة في عملية

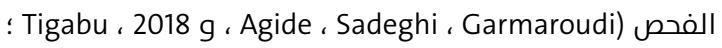

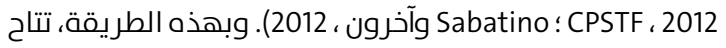
للنساء الفرصة لطرح الأسئلة، ويتم الحد من العوائق وتقديم ، الإجابات على استفساراتهن ومخاطبة مخاوفهن.

تحتاج الممرضات إلى الحصول على تدريب منتظمم حول سرطان الثدي والأولويات الصحية لدولة الإمارات العربية المتحدة لضمان ثقتهن في نقل المعلومات الدقيقة والصحيحة للمرضس، ومساعدتهن على تقديم الردود تجاه استفسارات

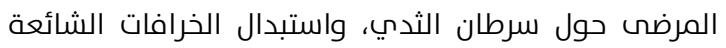
والمعتقدات الباطلة بالحقائق. في حين أن الممرضات في دراستنا تعلموا المعلومات عن سرطان الثدي أثناء دراساتهم التمريضية، إلا أن القليل منهم حصلوا على دورات تدريبية حول سرطان الثدي بصفة ممرضات مؤهلات، لكنهم اعتقدوا أن ذلك مهم وستعزز ثقتهن بشكل كبير بعد حضور ورش

$$
\text { العمل التدريبية. }
$$

يعد الاتصال بالنساء لمساعدتهم على تحديد مواعيد إجراء الفحص أكثر فاعلية من الطلب منهن إجراء تصوير الثدي

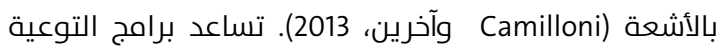

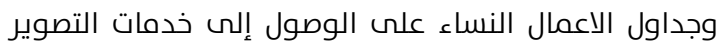
الشعاعي للثدي بشكل فردي، وتخاطب مخاوفهن، وتقوم بتوعيتهن بالخدمات المجانية المتاحة (Drake وآخرين، 2015). نتج عن جداول الأعمال هذه زيادة معدلات المشاركة بشكل

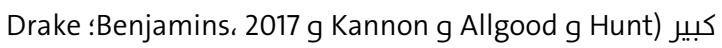

$$
\text { وآخرين، 2015). }
$$

يجب تذكير أفراد المجتمع بأهمية إجراء الفحوصات الصحية

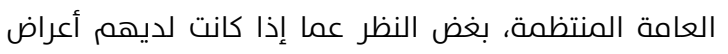

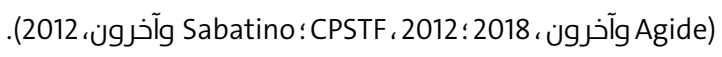
سيساعد ذلك على تعزيز ثقافة الصحة الوقائية، ويصبح فرصة جيدة لتثقيف أفراد المجتمع، ومخاطبة الأولويات الصحية لدولة الإمارات العربية المتحدة.

أظهرت الدراسات أن المنظمات واجهت صعوبات في جمع البيانات للمساعدة في تحديد ما إذا كان تنفيذ الاستراتيجيات يؤثر على خدمتهم، وكانوا يقاومون إنفاق الموارد والتمويل

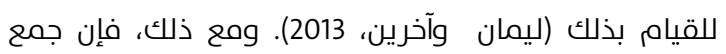
البيانات مهم لتحديد ما إذا كانت التحسينات أو زيادة الوصول دالهال إلى خدمات التشخيص والعلاج فعالة في الحد من معدلات
معظمهم لم يكونوا على دراية بحملات التوعية بسرطان الثدي التي تديرها منظمات أخرى، باستثناء القافلة الوردية Pink Caravan.

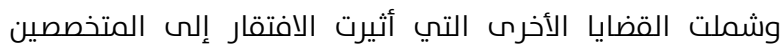
والعاملين في عيادات فحص الثدي، والحاجة إله إرسال المرضى خارج إمارة رأس الخيمة لعلاج السرطان، وتغطية تكاليف الفحص، وضيق الوقت والموارد لتنظيم الحملات.

للمساعدة في تخصيص المزيد من الوقت لتوعية المرضس، اعتقد معظم المشاركين أن الممرضات أو الموظفين المدربين الآخرين بإمكانهم زيادة وعي المجتمع قبل رؤية المرضى للطبيب. بالإمكان تنفيذ حملات توعية المرضس بشكل مجاميع، مع توفر

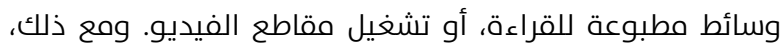
يجب ألا يمتد دور الممرضات إلى ما بعد توعية المرضى بأهمية إجراء فحص الثدي.

\section{5. تقييم فعالية الحملات}

لتقييم فعالية الحملات أو البرامج، ستقوم معظم المنظمات بتسجيل عدد المشاركات، وإرسال عدد النساء اللواتي أجروا الفحص وعدد الحالات الإيجابية لسرطان الثدي إلهات وإلهات وزارة الصحة. أكد المشاركون أنهم من المهم جداً وجود قاعدة بيانات وطنية شاملة للسرطان، وكان المشاركون داعمين لفكرة توفير البيانات لوزارة الصحة. تساعد هذه البيانات أيضًا المؤسسات على ضمان انهان استيفائها الحد الأدنى من عمليات الفحص المطلوبة من قبل وزارة الصحة لفحص الثدي. وشملت التقنيات الأخرى الته تم تنفيذها معرفة عدد الأشخاص الذين خضعوا للفحوصات بعد حضور حملة توعية، وإجراء اختبارات ما قبل وما بعد، والتحقق من الإعلانات التي الدي استجاب لها الناس، والتحقق من عدد النساء اللواتي ما زلن يخضعن لفحوصات متابعة.

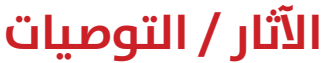

قدمت ورقة السياسة هذه نتائج توفر نظرة ثاقبة للتأثيرات السلوكية والبيئية على القرارات والمواقف الصحية. من المهم أن تكون العوائق التي تحول دون إجراء النساء لفحص سرطان الثدي معروفة ويجب أخذها في الاعتبار عند تشكيل السياسات وتخطيط برامج الفحص (أندرسون وآخرين، 2011). الوقاية من السرطان من خلال برامج الفحص هي طريقة فعالة من حيث التكلفة وتساعد أيضًا

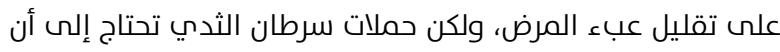
6 تتمكن من تحديد السكان المستهدفين، وتشجيعهم على المشاركة في الفحص المنتظم (العثمان وآخرون، 2015). تم تقديم التوصيات التالية للمساعدة في تعزيز الفوائد من حملات سرطان الثدمي: 1. خلال المناقشات الجماعية المركّزة، كانت التكلفة أحد الاعتبارات الرئيسية للمشاركين، وتم تقديم فحص مخفض التكلفة أو المجاني، ولكن غالبًا ما كانت تقتصر على شهر أكتوبر. يؤدي خفض التكلفة التي تدفعها المرأة لإجراء الفحص إلى زيادة معدلات المشاركة في الفحص (بارون وآخرون، 2008؛ فريق عمل المعني بالخدمات الوقائية المجتمعية (CPSTF ، 2012 Sabatino وآخرون، 2012) ولكن يجب توفير خدمات فحص الثدي المجانية على مدار العامم في إمارة رأس الخيمة، أو الأموال من الهيئات العامة والخاصة لدعمم تكاليف الفحص بالنسبة للنساء اللواتي لا يستطعن تحمل هذه النفقات. 
العلاج في الخارج لأنه أرخص. من الضروري أن تمتلك دولة الإمارات الموارد الكافية لتلبية احتياجات سكانها دون تأخير في علاج مرض السرطان، وينبغي أن تكون كل إمارة مستقلة أيضًا في تقديم خدماتها. يجب استخدامم البيانات من سجلات السرطان الوطنية والمستشفيات وأرقام قوائم الانتظار ومراقبتها لضمان تلبية الاحتياجات وزيادة القدرة على ضمان حصول المرضس على العلاج والرعاية دون تأخير. وتشمل التوصيات الأخرى ما يلي: أ. إنشاء طريقة أكثر داعمة لإجراء تصوير الثدمي بالأشعة.

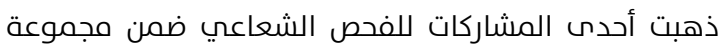
نساء، وكان هذا الاقتراح شائع بين بقية المشاركات. بسبب التوتر المصاحب لعملية الفحص، خاصة بين النساء الإماراتيات،

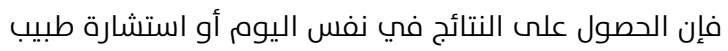
فورًا بعد إجراء الفحص سيساعد على التخفيف من شدة التوتر. يجب تشجيع العيادات على إتباع ممارسات مماثلة، ويجب دعم إدماء العيادات التي تتبع هذا النظامم بالفعل على الدوام.

ب. يجب أن تكون خدمات الفحص متاحة في كل من الخدمات العامة والخاصة لأنه من خلال مناقشات مجموعة التركيز لدينا، فضلت النساء الإماراتيات الخدمات العامة في حين تميل النساء غير الإماراتيات إله استخدامم الخدمات الخاصة. ج. استخدام وسائل التواصل الاجتماعي، ولاسيما خدمة واتساب لمشاركة المعلومات حول المواضيع الصحية والحملات

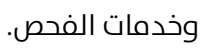

الوفيات وعبء المرض (آندرسون وآخرين، 2011). علس هذا النحو، من الضروري أن ترسل جميع المنظمات التي لديها خدمات فحص البيانات إله وزارة الصحة وأن يكون لديها نظامم لرصد الأمراض غير المعدية، وإلا ستكون هناك صعوبات لمراجعة التقدم المحرز في معالجة عبء الأمراض (العثمان

$$
\text { وآخرين، 2015). }
$$

تتطلب المبادئ التوجيهية الخاصة بسرطان الثدي في وزارة الصحة الإماراتية (2014) من عيادات سرطان الثدي إكمال 1000

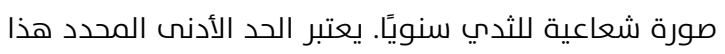

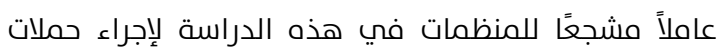

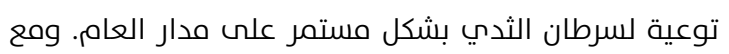
ذلك، تحتاج عيادات الثدي إله الدعم والموارد لتلبية الحد الأدنس من المتطلبات. أوصت دول مجلس التعات التهات التعات الخليجي بالتعاون معًا عند التأكد من تجهيز مراكز الرعاية الصحية دول دول لتعليم وتشخيص السرطان، وضمان جودة الخدمات والمعدات وتقديم الخدمات في الوقت المناسب (العثمان وآخرون، 2015)، ويجب تطبيق هذه العوامل في عيادات فحص سرطان الثدي للمساعدة في ضمان قدرتهم عله تلبية إرشادات

وزارة الصحة.

9. جزء من الموارد والخدمات المقدمة لمرضى السرطان لم يكن المشاركون على علم بأي علاج متوفر للسرطان في إمارة

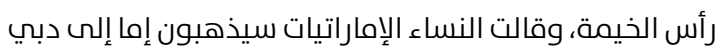

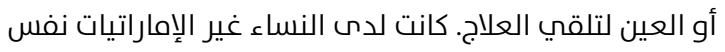
الرأي، ولكن ذكروا أنهم لن يترددوا في السفر من أجل تلقي

\section{شْكر وتْدـير}

يود مؤلفو هذه الدراسة أن يشكروا مؤسسة الشيخ سعود بن صقر القاسمي لبحوث السياسة العامة على دعمهم ومساعدتهمم

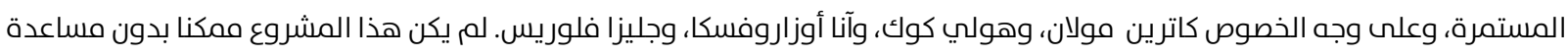
الموظفين من مستشفى رأس الخيمة وجامعة رأس الخيمة للطب والعلوم الصحية. على وجه الخصوص، نود أن نشكر الدكتور شكرمي آدم من جامعة رأس الخيمة للطب والعلوم الصحية والسيدة سو أيكن من مستشفص رأس الخيمة على الإعلان عن الدراسة وتوظيف المشاركين

المؤلفون

الآنسة دانيا أبو عواد هي طالبة دكتوراه في تخصص العلوم السلوكية والاجتماعية في مجال الصحة بجامعة سيدني. الدكتورة سيدة زكية حسين هي محاضرة أوله ومديرة دورة بكالوريوس العلوم الصحية بجامعة سيدني. وهي مختصة في مجموعة من أبحاث صحة المرأة في أستراليا وعلى المستومن الدولي. وهي رئيسة الباحثين في الدراسة. الأستاذ المساعد مارتن ماكي هو مساعد عميد أبحاث التعليمم بكلية العلوم الصحية بجامعة سيدني، وباحث مشارك رئيسي في هذه الدراسة. البروفيسور باتريك برينان هو قائد مجموعة التصوير الشعاعي والتحسين والإدراك MIOPeG في جامعة سيدني. تضمنت أبحاثه طرق تصوير رئيسية بما في ذلك الأشعة السينية والتصوير المقطعي المحوسب والموجات فوق الصوتية والتصوير بالرنين المغناطيسي، مع بـاني التركيز بشكل خاص على تصوير الثدي والصدر. وهو باحث مشارك رئيسي في هذهة فئه الدراسة. 


\section{References}

Agide, F., Sadeghi, R., Garmaroudi, G., \& Tigabu, B. (2018). A systematic review of health promotion interventions to increase breast cancer screening uptake: from the last 12 years. European Journal of Public Health, 28(6), 1149-1155. https://doi.org/10.1093/eurpub/ckx231

Albeshan, S. M., Mackey, M. G., Hossain, S. Z., \& Brennan, P. C. (2018). Transforming breast cancer diagnosis in Ras Al Khaimah (Sheikh Saud Bin Saqr Al Qasimi Foundation for Policy Research Policy Paper No. 25). http:// dx.doi.org/10.18502/aqf.0057

Al-Madouj A. N., Eldali, A., \&t Al-Zahrani A. S. (2011). Ten-Year cancer incidence among nationals of the GCC states 1998-2007. Riyadh, Saudi Arabia: King Faisal Specialist Hospital and Research Center.

Al-Othman, S., Haoudi, A., Alhomoud, S., Alkhenizan, A., Khoja, T., \&t Al-Zahrani, A. (2015). Tackling cancer control in the Gulf Cooperation Council Countries. The Lancet Oncology, 16(5), e246-e257. https://doi.org/10.1016/ S1470-2045(15)70034-3

Al-Sharbatti, S., Shaikh, R., Mathew, E., \& Albiate, M. (2013). Breast self examination practice and breast cancer risk perception among female university students in Ajman. Asian Pacific Journal of Cancer Prevention: APJCP, 14(8), 4919-4923. https://doi.org/10.7314/APJCP.2013.14.8.4919

Anderson, B., Cazap, E., El Saghir, N., Yip, C., Khaled, H., Otero, I., ... Harford, J. (2011). Optimisation of breast cancer management in low-resource and middle-resource countries: executive summary of the Breast Health Global Initiative consensus, 2010. Lancet Oncology, 12(4), 387-398. https://doi.org/10.1016/S14702045(11)70031-6

Baron, R., Rimer, B., Coates, R., Kerner, J., Kalra, G., Melillo, S., ... Leeks, K. (2008). Client-Directed Interventions to Increase Community Access to Breast, Cervical, and Colorectal Cancer Screening. American Journal of Preventive Medicine, 35(1), S56-S66. https://doi.org/10.1016/j.amepre.2008.04.001

Brown, R., Kerr, K., Haoudi, A., \& Darzi, A. (2012). Tackling cancer burden in the Middle East: Qatar as an example. Lancet Oncology, 13(11), e501-e508. https://doi.org/10.1016/S1470-2045(12)70461-8

Camilloni, L., Ferroni, E., Cendales, B., Pezzarossi, A., Furnari, G., Borgia, P., ... Ferroni, E. (2013). Methods to increase participation in organised screening programs: a systematic review. BMC Public Health, 13(1), 464-464. https://doi.org/10.1186/1471-2458-13-464

Cancer Council Australia. (2018). Understanding breast cancer a guide for people with cancer, their families and friends. Retrieved from the Cancer Council website: https://www.cancer.org.au/about-cancer/types-ofcancer/breast-cancer/

Chouchane, L., Boussen, H., \& Sastry, K. (2013). Breast cancer in Arab populations: molecular characteristics and disease management implications. Lancet Oncology, 14(10), e417-e424. https://doi.org/10.1016/S14702045(13)70165-7

Community Preventive Services Task Force. (2012). Updated Recommendations for Client- and Provider-Oriented Interventions to Increase Breast, Cervical, and Colorectal Cancer Screening. American Journal of Preventive Medicine, 43(1), 92-96. https://doi.org/10.1016/j.amepre.2012.04.008

Drake, B., Tannan, S., Anwuri, V., Jackson, S., Sanford, M., Tappenden, J., ... Colditz, G. (2015). A Community-Based Partnership to Successfully Implement and Maintain a Breast Health Navigation Program. (Report), 4O(6), 1216-1223. https://doi.org/10.1007/s10900-015-0051-z

Elobaid, Y., Aw, T., Grivna, M., \&t Nagelkerke, N. (2014). Breast cancer screening awareness, jnowledge, and practice among Arab women in the United Arab Emirates: A Cross-Sectional Survey. PLoS ONE, 9(9), e105783. https://doi.org/10.1371/journal.pone.0105783

Elobaid, Y., Aw, T., Lim, J., Hamid, S., \&t Grivna, M. (2016). Breast cancer presentation delays among Arab and national women in the UAE: a qualitative study. SSM - Population Health, 2, 155-163. https://doi. org/10.1016/j.ssmph.2016.02.007

Hunt, B., Allgood, K., Kanoon, J., \&t Benjamins, M. (2017). Keys to the Successful Implementation of CommunityBased Outreach and Navigation: Lessons from a Breast Health Navigation Program. Journal of Cancer Education, 32(1), 175-182. https://doi.org/10.1007/s13187-015-0904-2 
International Agency for Research on Cancer. (2018a). Estimated number of deaths in 2018, Western Asia, all cancers, females, all ages. Retrieved December 14, 2019, from http://gco.iarc.fr/today/home

International Agency for Research on Cancer. (2018b). Estimated number of deaths in 2018, United Arab Emirates, all cancers, females, all ages. Retrieved December 14, 2019, from http://gco.iarc.fr/today/home

Kuykendall, S. (2018). Encyclopedia of public health: principles, people, and programs. Santa Barbara, California: Greenwood.

Leeman, J., Moore, A., Teal, R., Barrett, N., Leighton, A., \&t Steckler, A. (2013). Promoting Community Practitioners' Use of Evidence-Based Approaches to Increase Breast Cancer Screening. Public Health Nursing, 30(4), 323-331. https://doi.org/10.1111/phn.12021

Rabbani, S. A., Mutasem, H., Naser, R. A., \& Hussein, Y. (2017). Awareness and perception of breast cancer among the future healthcare providers of Ras Al Khaimah, United Arab Emirates. Journal of Applied Pharmaceutical Science, 7(2), 142-146. doi: 10.7324/JAPS.2017.70219

Ravichandran, K., \& Al Zahrani, A. (2009). Association of reproductive factors with the incidence of breast cancer in Gulf Cooperation Council countries. Eastern Mediterranean Health Journal, 15(3), 612-621. https://doi. org/10.26719/2009.15.3.612

Sabatino, S., Lawrence, B., Elder, R., Mercer, S., Wilson, K., Devinney, B., ... Glanz, K. (2012). Effectiveness of Interventions to Increase Screening for Breast, Cervical, and Colorectal Cancers. American Journal of Preventive Medicine, 43(1), 97-118. https://doi.org/10.1016/j.amepre.2012.04.009

So, V., Channon, A., Ali, M., Merdad, L., Al Sabahi, S., Al Suwaidi, H., ... So, V. (2018). Uptake of breast and cervical cancer screening in four Gulf Cooperation Council countries. European Journal of Cancer Prevention, $0(0)$, 1-6. https://doi.org/10.1097/CEJ.0000000000000466

United Arab Emirates Ministry of Health and Prevention. (2014). The national guidelines for breast cancer screening and diagnosis. Retrieved from the Insurance System for Advancing Healthcare in Dubai website: http://www.isahd.ae/Home/LawAndRegulations

United Nations Children's Fund. (2014). MODULE 1: What are the Social Ecological Model (SEM), Communication for Development (C4D)?. Retrieved from https://www.unicef.org/cbsc/files/Module_1_SEM-C4D.docx

World Health Organisation. (2007). Cancer control: Early detection WHO guide for effective programmes. Retrieved from the World Health Organisation website: https://www.who.int/cancer/publications/cancer_ control_detection/en/ 



تهدف سلسلة أوراق السياسة الخاصة بمؤسسة الشيخ سعود بن صقر القاسمي لبحوث السياسة العامة إلى نشر بحوث الأفراد و المؤسسات التي تهتم و تركز على تنمية السياسة العامة في العالم العربي. و تعبر النتائج و الاستنتاجات عن آراء أصحابها المؤلفين و و تعتبر كمرجع لمؤسسة الشيخ سعود بن صقر القاسمي لبحوث السياسة العامة.

\section{مؤسسة الشُيخ سعود بن صقر القاسماي لبحوثُ السياسةٌ العامهة}

$$
\text { تطويرالبحوث، ودعم العقول }
$$

تقع مؤسسة الشيخ سعود بن صقر القاسمي لبحوث السياسة العامة في رأس الخيمة وهي مؤسسة غير ربحية تأسست في عام 9..· تحت رعاية صاحب السمو الشيخ سعود بن صقر القاسمي، حاكم إمارة رأس الخيمة. وللمؤسسة ثلاث وظائف رئيسية:

$$
\text { إعلام صانعي السياسات عن طريق إجراء وتكليف البحوث ذات الجودة العالية، }
$$

إثراء القطاع العام المحلي، وخاصة التعليم، من خلال تزويد التربويين وموظفي الحكومة فيرأس الخيمة بالمواد اللازمة لإحداث تأثير إيجابي على العلى مجتمعهم، بناء روم الجماعة والتعاون والرؤية المشتركة من خلال المشاركة الهادفة التي تعزّز العلاقات بين الأفراد والمؤسسات. لمعرفة المزيد عن أعمالنا البحثية، والمنم، والأنشطة، والبرامج يرجى زيارة موقعنا: www.alqasimifoundation.com 